\title{
O FUTURO DO PASSADO: IMIGRANTES BRASILEIROS EM PORTUGAL E DIFERENTES ENTRELAÇAMENTOS
}

\author{
Igor José de Renó Machado*
}

\begin{abstract}
Neste artigo proponho uma especulação sobre a situação presente da migração brasileira em Portugal a partir de dois conjuntos de etnografias produzidas no passado, consideradas como sítios arqueológicos para entender a situação contemporânea. Esses trabalhos revelam diferentes maneiras de inserção na sociedade portuguesa pelos imigrantes brasileiros, indicando probabilidades de novas migrações ou de migrações de retorno ao Brasil.
\end{abstract}

Palavras-chave: imigração brasileira em Portugal, crise econômica Portuguesa, migrações de retorno.

\section{Introdução ${ }^{1}$}

Este artigo tenta observar os fatos presentes à luz daquilo que se passou num passado relativamente recente. A partir da minha experiência de campo entre imigrantes brasileiros em Portugal em 2000 e a partir dos trabalhos produzidos pelo grande projeto que coordeno sobre a família do emigrante valadarense (2007-2012), tentarei dar sentido à complexidade da situação presente. Vemos um cenário de retorno dos emigrantes internacionais brasileiros num volume aparentemente menor que o esperado, assim como a diminuição da imigração brasileira em Portugal, mas também abaixo do que se imaginaria para a atual crise Portuguesa.

Em 2007, um livro coordenado por Jorge Malheiros² procurava sintetizar aquilo que sabemos sobre a imigração brasileira em Portugal. O livro tratava de várias dimensões, desde as construções identitárias até as dinâmicas no mercado de trabalho. Quero lembrar esse livro por conta do interessante capítulo final:

Professor adjunto da Universidade Federal de São Carlos. São Carlos - SP/Brasil.

1 Texto apresentado originalmente no Seminário Imigração e Emigração Internacional no Cenário de Mudanças Globais no Início do Século XXI: as relações entre o Brasil e os países da Península Ibérica, Belo Horizonte, PUC Minas, 06 a 07 de junho de 2013.

2 MALHEIROS, Jorge Macaísta (org.). Imigração brasileira em Portugal. 
como forma de terminar a reflexão sobre o tema, alguns autores tentavam oferecer um panorama futuro da migração brasileira em Portugal. Ato sempre temerário, claro, pois a sociedade é renitentemente avessa às regularidades: coisas surpreendentes acontecem.

Aquele futuro imaginado agora é um pouco passado (são já seis anos que lá se vão). E aquele quadro pintado sugere mais uma reflexão sobre o impacto da imigração brasileira em Portugal que propriamente uma análise perspicaz sobre o futuro. Os cientistas sociais são péssimos com a bola de cristal. Dizia-se no texto “certamente o processo de reunião familiar continuará a sustentar o movimento na próxima década, devendo-se também assumir-se que o retorno será mais intenso do que se imagina e que diversas remigrações para países terceiros acontecerão" ${ }^{\prime 3}$ e, a seguir, "De qualquer forma a presença de um fluxo constante de imigrantes brasileiros será ainda uma realidade presente nos próximos anos" ${ }^{\prime 4}$.

O foco dessa dúvida era o princípio de contraste entre o desenvolvimento da economia brasileira e a estagnação da economia portuguesa. Outro dado era uma percepção de um inevitável endurecimento das políticas migratórias em Portugal. Naquele ano, em 2007, se promulgou uma nova lei de imigração em Portugal, que analisamos extensamente em outros dois artigos 5 . A lei, entretanto, não era tão dura e restritiva à entrada de brasileiros. De certa forma, era até uma legislação menos restritiva que as demais europeias.

Algo aconteceu entre o 2007 e futuro previsto nesse livro: a crise de 2008 e seus desdobramentos até a situação presente. Se em 2007 o cenário era de um crescimento modesto, a realidade se transformou num decrescimento radical, uma ascensão sem precedentes da taxa de desemprego portuguesa e uma diminuição da imigração brasileira em Portugal. O ressecamento das oportunidades de emprego, a emigração recente de portugueses para países europeus, África e mesmo para o Brasil, não faziam parte nem do mais desastroso cenário que se poderia imaginar em 2007. Portugal sente a crise de forma aguda, bastam alguns números para o confirmar: o corte de benefícios sociais, a recessão econômica, a diminuição de postos de trabalho. E para piorar a situação, como afirmam Padilha e Ortiz ${ }^{6}$ e também Nunan e Peixoto ${ }^{7}$, a taxa de desemprego entre imigrantes é muito maior que entre os nacionais.

CARNEIRO et alii, p. 197.

4 Ibidem.

5 MACHADO, Igor J. R. A condição obscura: Reflexões sobre as políticas de imigração e controle de estrangeiros em Portugal; IDEM. The Management of Difference Reflections on policies concerning immigration and the control of foreigners in Portugal and Brazil.

6 PADILLA, Beatriz; ORTIZ, Alejandra. Fluxos imigratórios em Portugal: do boom migratório à desaceleração no contexto de crise. Balanços e desafios, p. 178.

7 NUNAN, Carolina; PEIXOTO, João. Crise econômica e retorno dos imigrantes brasileiros em Portugal, p. 233. 
Ao mesmo tempo, o Brasil sofreu muito menos com a crise mundial: temos tido um crescimento modesto (com um pico fora da curva em 2010 - média simples de 3.3\% na última década), mas acompanhado de uma economia de pleno emprego. Essa parte da previsão não estava de todo errada, assim como a ideia de que iríamos ver migrações de retorno e remigrações. Se contrastarmos a decaída da economia portuguesa e a relativa estabilidade da economia brasileira, não é de espantar a diminuição da imigração brasileira em Portugal, mas também não estamos diante de uma simples matemática entre níveis de emprego aqui e desemprego lá. Isso porque essa migração de retorno e a diminuição da migração brasileira em Portugal não são proporcionais à crise que se instalou em Portugal.

Temos visto evidências de imigração de retorno, ao mesmo tempo em que temos visto evidências de fortes processos de remigração para países menos afetados pela crise. Mas temos visto que essas voltas e remigrações são, de certa forma, menos intensas que a crise em si. Neste artigo tratarei de algumas evidências desses processos e procurarei corrigir o futuro errado daquele texto de 2007. Afinal, era eu mesmo um dos autores daquele texto. Ao final, buscarei algumas evidências do passado que sustentam esse desencaixe, para isso usarei meu trabalho de 2003 como referência, como uma espécie de momento já historiográfico da imigração em Portugal, bem como minhas pesquisas em Valadares com imigrantes que se deslocaram para Portugal.

\section{Desencaixe}

Vemos que há um descasamento temporal entre o que acontece na economia e a dinâmica dos fluxos migratórios: as coisas não são mecânicas e automáticas. Embora o retorno esteja aumentando significativamente, ele não corresponde exatamente aos movimentos da economia. No caso de brasileiros em Portugal, no auge do crescimento brasileiro da última década, em 2010, houve ainda um aumento de 2,7\% da imigração brasileira em Portugal e em 2011 vimos uma pequena diminuição, que parece continuar em 2012 (apesar do crescimento do PIB em 2012 ter sido frustrante). Esse descasamento é natural, já que as decisões de migrar são complexas e envolvem muito esforço e sacrifício pessoal. Da mesma forma devemos encarar o retorno, já que voltar antes do planejado é assumir o fracasso dos planos, é voltar sem os recursos necessários, e voltar sem saber exatamente o que fazer no Brasil. Os imigrantes tendem a esperar mais um pouco para ver se devem voltar e pesa muito na decisão a possibilidade de uma remigração para outro país que talvez esteja em situação melhor.

No mesmo texto de 2007, dizíamos: "Portugal vai cada vez mais aparecer como um nexo importante de toda a emigração brasileira para a Europa, como uma espécie de plataforma de lançamento" ${ }^{\prime \prime}$. Essa observação não se provou de

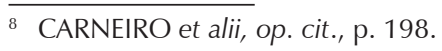


todo errada e, embora num outro contexto (o de crise econômica severa), Portugal parece ter se colocado de fato como plataforma de realocação da migração brasileira na Europa. Cito um exemplo indireto: ao final do ano passado, recebi um convite de um colega inglês interessado em investigar o súbito aumento de brasileiros numa cidade inglesa, no auge da crise europeia. Montamos um projeto de pesquisa e estamos agora esperando o resultado da avaliação: mas a questão central do projeto é a remigração de brasileiros de Portugal e Espanha para o Reino Unido.

Aqui seria bom separar os processos de remigrações do processo de retorno (embora esse último possa ser seguido de uma remigração, como é o caso em muitas situações). A remigração é a continuidade de um projeto familiar, pessoal e social, deslocado para outro país por conta das dificuldades presentes naquele que era o "alvo inicial". Esse deslocamento não é simples, mas ainda é uma opção antes do retorno para o Brasil em muitos casos. Nesse cenário de crise é um palpite seguro afirmar que as remigrações estão aumentando, e que países europeus com menos impacto da crise (UK e Alemanha) devem ser os alvos preferenciais dessas movimentações. Sobre essas questões é provável que tenha algo a dizer a partir do ano que vem, quando a pesquisa vai acontecer de fato.

Mas, de qualquer forma, temos indícios que a migração de retorno é significativa. Segundo comunicado do Itamaraty ${ }^{9}$, o número de brasileiros no exterior diminuiu em 20\% nos últimos anos (passando de 3 para 2,5 milhões). Em função disso, o Itamaraty resolveu criar um portal de internet para auxiliar o retorno de brasileiros ${ }^{10}$. O BID ${ }^{11}$, por sua vez, em levantamento anual indica uma diminuição geral das remessas de brasileiros, mas em 2012 vemos um pequeno aumento de 0,8\% em relação às remessas de 2011, indicando uma estabilidade. Por outro lado a OIM indica que imigrantes brasileiros têm se candidatado em volumes significativos ao Programa de Retorno Voluntário. Nunan e Peixoto ${ }^{12}$ indicam a manutenção de um fluxo de entrada mesmo na crise, embora os números mais recentes (2011) já indiquem até mesmo a redução do número de brasileiros em Portugal. Mas de qualquer ângulo, permanece uma resiliência grande da migração brasileira em Portugal.

Como se vê temos notas contraditórias, indicando um fluxo de retorno, mas ao mesmo tempo indicando que talvez ele não seja tão expressivo como a crise poderia fazer pensar. E há que se diferenciar os fluxos de forma geral: há retornos intensos de Japão (esses precisamente documentados) e do Paraguai (conforme censo de 2010). O retorno dos EUA e Europa parece ser menos

${ }_{9}$ Cf. <http://sistemas.mre.gov.br/kitweb/datafiles/Retorno/pt-br/file/Portal\%20do\%20Retorno\%2Re lease.pdf $>$.

${ }^{10} \mathrm{Cf} .<$ http://retorno.itamaraty.gov.br/pt-br/>.

${ }^{11}$ Cf. "Com crise, volume de remessas de brasileiro no exterior fica estável". Disponível em: < http://oglobo. globo.com/economia/com-crise-volume-de-remessas-de-brasileiro-no-exterior-fica-estavel-8237327>.

12 NUNAN, PEIXOTO, op. cit. 
intenso e talvez indique uma tentativa de permanecer e esperar a crise arrefecer. Ou talvez haja outras particularidades na imigração brasileira para esses países que faça a migração de retorno menos intensa.

E se a língua portuguesa era e é um patrimônio comum, grande mecanismo de agenciamento das escolhas de migração de muitos brasileiros (como demonstramos em Valadares), criando um ambiente de interação mais profícuo que o de outros países, o mesmo se faz ver em sentido contrário. A nova onda de migrações portuguesas tem o Brasil como um dos destinos ${ }^{13}$. Se bem que restritas a uma emigração mais qualificada e pronta para assumir lugares no mercado de trabalho mais qualificado brasileiro, parece evidente que podemos pensar na língua como um corredor de passagem nos dois sentidos (na verdade múltiplos destinos, considerando-se os PALOPs). O que podemos ver é que historicamente as relações intensas entre pessoas, empresas, governos e famílias dos dois lados do atlântico deixam traços nesses corredores de passagem, ora ativando um, ora outro dos destinos. O fato é que portugueses continuam tendo certos benefícios legais no Brasil, mesmo que um conjunto de dificuldades práticas e cotidianas seja também a regra geral.

Por outro lado, Ferreira e Ramos ${ }^{14}$ indicam que o número de casamentos mistos entre portugueses e brasileiros em Portugal é alto, chegando a atingir $9 \%$ do total de casamentos em 2009. Essa é uma cifra muito significativa: os brasileiros eram 111.455 pessoas ${ }^{15}$ em 2011 (dados do SEF), e a população residente em Portugal era de 10.562.178 em 2011 (dados do INE). Numa aproximação muito grosseira (apenas para reforçar o argumento) podemos dizer que algo em torno de $1 \%$ da população de Portugal é composta de brasileiros e esse $1 \%$ participa de $9 \%$ do total de casamentos no país.

Mas as conexões familiares causadas por esses parentescos criados recentemente talvez ainda levem algum tempo para serem ativadas no mecanismo de migração de portugueses para o Brasil: o casamento de brasileiras e brasileiros com portugueses/as é majoritariamente entre brasileiros com mais instrução que os portugueses, indicando uma inserção nas camadas mais baixas da sociedade portuguesa. As evidências da emigração portuguesa recente indicam que essa mão-de-obra menos qualificada portuguesa segue para outros países europeus, enquanto os que migram para Angola e Brasil são mais qualificados (de certa forma espelhando o cenário inicial da migração brasileira em Portugal). A lógica seria que com o passar dos anos e a continuidade da crise portuguesa (e se não o crescimento, ao menos a estagnação da economia brasileira), veríamos aumentar

13 PADILLA, ORTIZ, op. cit., p. 162.

${ }^{14}$ FERREIRA, Ana Cristina; RAMOS, Madalena. Padrões de casamento dos imigrantes brasileiros residentes em Portugal.

${ }^{15}$ Sem contar os não documentados. 
esse fluxo de imigração portuguesa menos qualificada e com relações com os imigrantes brasileiros atualmente em Portugal. Mas isso é uma futurologia.

\section{Evidências anteriores}

Olhando para essa situação presente, cujo caráter é um tanto ambíguo, penso em dar alguma contribuição para o desatar dos nós. Essa contribuição vai olhar para um passado recente e tentar identificar ali algumas explicações plausíveis para essa situação presente: é como uma escavação arqueológica em busca de relações factíveis com a situação presente. Os dois sítios arqueológicos dos quais farei uso são duas situações etnográficas distintas: o meu trabalho de campo entre brasileiros no Porto em 2000 (na verdade, em 1998, 2000 e 2002), e os trabalhos de campo de uma equipe de alunos em Governador Valadares (que se estenderam entre 2006 e 2012).

Nessas duas situações vemos dinâmicas distintas de enfrentamento do processo migratório, constituindo formas divergentes de relação com a sociedade portuguesa e das quais podemos deduzir formas alternativas de possibilidade de retorno. Veremos que uma variável muito relevante nesses dois exemplos é o status civil do imigrante: solteiro ou casado. A inserção no mercado de trabalho também se revela fundamental. Os casos nos permitem pensar em como se encara um processo de crise, tendo como parâmetro as relações que os brasileiros estabelecem com os portugueses e não a crise em si.

\section{Os brasileiros em 2000}

O ano de 2000, especificamente, marcou uma virada na percepção sobre a imigração brasileira. O debate sobre as características da migração brasileira concordam que a partir da virada do milênio a migração brasileira "proletarizou-se". Se antes tínhamos níveis de instrução altos, qualificações específicas (publicitários, dentistas etc.), passamos a ter a entrada massiva em Portugal de imigrantes para trabalhar nos setores tradicionais de ocupação imigrante: hotelaria, construção civil, serviços de limpeza e cuidado de idosos. Há vasta bibliografia sobre o assunto, por isso não me estenderei sobre isso.

$\mathrm{O}$ ano era o de viragem e o meu trabalho de campo acompanhou uma "comunidade" de brasileiros no Porto, cujas características eram, digamos, de transição: era um grupo predominantemente masculino, com instrução média, vivendo em Portugal já há algum tempo. Tinham semelhanças com o que ficou conhecido como "primeira vaga" da imigração brasileira. Entretanto, no mercado de trabalho, assemelhavam-se à "segunda vaga": estavam ligados principalmente à hotelaria, eram quase todos garçons, trabalhadores de restaurantes, churrasqueiros etc. Havia muito poucos trabalhadores da construção civil e mesmo trabalhadoras domésticas. 
A qualificação que fiz da relação desses brasileiros permite que hoje se fale em algo como um nicho étnico para brasileiros no mercado de trabalho português. Mostrei, em termos gerais, como a exploração por parte dos brasileiros, de estereótipos presentes em Portugal sobre o Brasil constituiu um espaço de trabalho (o "mercado da alegria") e também uma forma de constituir o que então chamei de identidades brasileiras no Porto. Hoje as chamaria de brasilidades, mas essa é uma outra conversa que remete a preocupações teóricas sobre a identidade que não cabem aqui ${ }^{16}$.

Em termos gerais, tínhamos homens que vieram solteiros, que se relacionavam com mulheres portuguesas em relacionamentos muito difíceis, mas também conheciam e se casavam com brasileiras em solo português. Não era uma migração familiar: não havia muitas pessoas com famílias para sustentar no Brasil. Ou seja, esses brasileiros tinham menos preocupação com o que acontecia economicamente no Brasil, pois olhavam sempre para um futuro em Portugal. Esse perfil de imigrantes pode ter diminuído com o tempo, mas não se encerrou. Houve é uma viragem de gênero: passamos a ver cada vez mais mulheres chegando nessa situação de descompromisso familiar (ou compromissos mais fracos), o que explica um maior casamento de brasileiras com portugueses. Voltaremos a isso no final.

\section{O caso valadarense}

Nossas pesquisas com famílias de emigrantes valadarenses, centrados nos bairros pobres de Valadares (vila dos Montes, Santa Rita 1), resultaram em alguns artigos sobre a relação dessa migração com Portugal ${ }^{17}$. Demonstramos que tínhamos uma migração acentuada de pessoas casadas, deixando o cônjuge no Brasil e operando como target migrants ao longo de sua estadia em Portugal. Demonstramos como Portugal se tornou uma alternativa à medida que as restrições de entrada em solo norte-americano aumentavam. Demonstramos que a essência dessa movimentação é a constituição de um parentesco específico para os momentos de migração, quando os entes estão ausentes. Esse modelo opera com a separação durante alguns anos e com o projeto de reorganização da família após a migração (o que nem sempre acontece, como demonstramos).

Com fortes conotações religiosas, principalmente evangélicas, esses migrantes desenvolviam em Portugal um estilo de vida muito diferente daqueles brasileiros no Porto de quem falei antes: se esses buscavam constituir suas agendas de vida, digamos assim, a partir da visibilidade pública de sua presença,

${ }^{16}$ Cf. MACHADO, Igor José R. Kinship and Differentialities: Alternatives to Identity and to Ethnic Frontiers in The Study of Migrations.

17 MACHADO, Igor José R.; REIS, Ellen Saraiva. Algumas conclusões acerca do fluxo de valadarenses para Portugal; MACHADO, Igor José R.; ALMEIDA, Alexandra Gomes de; REIS, Ellen Saraiva. Algumas características do fluxo migratório de brasileiros de Governador Valadares para Portugal. 
os valadarenses iam em sentido contrário: buscavam a invisibilidade, a discrição e apoio em comunidades religiosas. Os imigrantes valadarenses tendiam a trabalhar em períodos duplos, com jornadas estafantes de trabalho na tentativa de acumular o máximo de recursos e maximizar as remessas. Identificamos uma concentração de valadarenses que vivia na costa da Caparica, lugar que ficou famoso em Portugal pela presença de muitos brasileiros (tendo sido inclusive inventada a incrível cena de um arrastão promovido por brasileiros que não aconteceu).

A tendência desses imigrantes fixarem-se em Portugal ou casarem-se por lá era menor que a do primeiro grupo, como podemos imaginar. A experiência da imigração era vista por eles como uma espécie de suspensão da própria vida em função do acumulo de recursos para completar seus sonhos do Brasil. Obviamente, esse projeto era cheio de riscos: riscos de saúde, de dissolução do casamento, de deportação, de sofrimentos pela ausência da família etc. Já os brasileiros naquele distante Porto de 2000 viviam suas vidas em Portugal e investiam todas as suas forças nessa perspectiva: o futuro era Portugal.

\section{Conclusões}

Pois bem, o que essas duas experiências tão distintas nos têm a dizer sobre o que se passa hoje em Portugal? Tomemos essas duas situações como extremos entre os quais uma gama variada de posicionamentos pode ser distinguida ${ }^{18}$. Elas nos dizem que aqueles que seguiram o caminho de uma inserção mais intensa em Portugal terão muito mais dificuldade em abrir mão de viver naquilo que constituíram como suas vidas ao longo de muitos anos. E muitos desses brasileiros que fizeram essas opções têm hoje familiares portugueses, filhos portugueses, têm uma vida que não pode ser simplesmente ignorada. Uma volta ao Brasil seria, efetivamente, enfrentar um mundo completamente novo e para o qual não se prepararam (coisa que vimos acontecer com os brasileiros que tiveram que voltar do Japão, por exemplo). Não investiram dinheiro no Brasil, não conhecem mais o país, não passaram pelas mudanças no Brasil da última década. Ou seja, o entrelaçamento intenso de redes de parentesco em solo português torna muito mais difícil um segundo deslocamento desses imigrantes, agora de volta para um país que eles decidiram deixar para trás.

Por outro lado os imigrantes que tiveram uma experiência mais próxima daquela dos valadarenses que conhecemos em nossas pesquisas estão muito mais propensos a sair de Portugal, já que o envolvimento deles com o país é mínimo. Mas ao mesmo tempo, esses migrantes têm objetivos específicos e voltar antes de completá-los é uma enorme dificuldade, já que significaria um fracasso em vários sentidos. Uma opção sempre presente, e que já identificamos em alguns exemplos concretos, é simplesmente continuar os planos em outro

${ }_{18}$ Ver o livro que publiquei em 2006 sobre a multiplicidade da imigração brasileira em Portugal: MACHADO, Igor José R. (org.). Um mar de identidades: a imigração brasileira em Portugal. 
lugar. Ou seja, esse projeto de imigração está mais propenso a uma remigração para outro país dentro da Europa e esse movimento certamente se fará sentir em Portugal e nos países que recebem esses migrantes.

Assim, podemos ver que a migração brasileira consolidou uma população em Portugal que nesse país permanecerá apesar da crise, principalmente por ter se entranhado no tecido social português: ainda veremos reunificações familiares e movimentos que contrariam a lógica econômica, simplesmente porque Portugal se tornou a casa desses brasileiros. Por outro lado, entre os migrantes menos conectados com a vida portuguesa, veremos e já vemos um movimento de remigração para outros países europeus. Os processos de retorno acontecem e continuaram a acontecer, principalmente com os imigrantes que estão a pouco tempo em Portugal, para quem o tempo e sacrifício investido ainda não são altos demais. É certo que essas são perspectivas gerais, e que há retornos em todos os contingentes de brasileiros, mas as pesquisas de cunho mais qualitativo podem nos ajudar a pensar as diferenças internas ao fluxo dos imigrantes brasileiros.

Os padrões de interação entre brasileiros e portugueses, que as pesquisas em 2000 já demonstravam, ou seja, o casamento de brasileiros mais qualificados com portugueses menos qualificados (que as pesquisas quantitativas constataram ser verdade) ainda indicam uma outra possibilidade migratória: o padrão propriamente português de emigração atual. Se há uma tendência dos portugueses menos qualificados em emigrar para países europeus em busca justamente do mercado de trabalho menos qualificado, talvez seja possível imaginar que uma porcentagem não insignificante desses leve consigo cônjuges brasileiros. Ou seja, se a crise portuguesa pode afetar os brasileiros que estão mais "emaranhados" no tecido social português, talvez sejam os padrões emigratórios portugueses que expliquem o processo. Ainda assim, teríamos remigrações para dentro da Europa.

A se pensar que o movimento português reproduza o que aconteceu com os brasileiros em Portugal (o que é apenas uma especulação), poderemos ver que a seguir a migração qualificada de portugueses para o Brasil, seguirá uma migração menos qualificada, nesse caso é provável que os primeiros a vir nesse modelo sejam justamente aqueles portugueses menos qualificados com cônjuges brasileiros. Assim, aqueles caminhos entrelaçados entre brasileiros e portugueses continuarão a se entrelaçar ainda mais.

\section{Bibliografia}

CARNEIRO, Roberto; CRISTÓVÃO Fernando; MACHADO Igor; MALHEIROS Jorge; PEIXOTO João. O futuro da imigração brasileira para Portugal: olhares, perspectivas e interrogações. In MALHEIROS, Jorge Macaísta. Imigração Brasileira em Portugal. Lisboa: ACIDI, 2007.

FERREIRA, Ana Cristina; RAMOS, Madalena. Padrões de casamento dos imigrantes 
brasileiros residentes em Portugal. Rev. bras. Est. Pop., Rio de Janeiro, v. 29, n. 2, jul./dez. 2012, p. 361-387.

MACHADO, Igor José R. (org.). Um mar de identidades: a imigração brasileira em Portugal. 1. ed. São Carlos: Edufscar, 2006.

. A condição obscura: Reflexões sobre as políticas de imigração e controle de estrangeiros em Portugal. Revista Crítica de Ciências Sociais, v. 92, 2011, p. 125-145.

. Kinship and Differentialities: Alternatives to Identity and to Ethnic Frontiers in The Study of Migrations. Vibrant (Florianópolis), v. 8, 2011, p. 220-235.

. The Management of Difference Reflections on policies concerning immigration and the control of foreigners in Portugal and Brazil. Vibrant (Florianópolis), v. 9, 2012, p. 313-332.

MACHADO, Igor José R.; ALMEIDA, Alexandra Gomes de; REIS, Ellen Saraiva. Algumas características do fluxo migratório de brasileiros de Governador Valadares para Portugal. Antropológicas (Porto), v. 11, 2009, p. 111-126.

MACHADO, Igor José R.; REIS, Ellen Saraiva. Algumas conclusões acerca do fluxo de valadarenses para Portugal. Teoria \& Pesquisa, v. 16, 2007, p. 153-166, 2007.

NUNAN, Carolina; PEIXOTO, João. Crise econômica e retorno dos imigrantes brasileiros em Portugal. REMHU, Rev. Interdiscip. Mobil. Hum., v. 20, n. 38, 2012, p. 233-250.

PADILLA, Beatriz; Alejandra Ortiz. Fluxos imigratórios em Portugal: do boom migratório à desaceleração no contexto de crise. Balanços e desafios. REMHU, Rev. Interdiscip. Mobil. Hum., v. 20, no 39, jul/dez 2012, p. 159-184.

\section{Abstract}

\section{The future from the past: Brazilian immigrants in Portugal and different interconnections}

In this article propose a speculation on the present situation of Brazilian migration in Portugal based on two sets of ethnographies produced in the past, considered as archaeological sites to understand the contemporary situation. These works reveal different ways of integration into Portuguese society by Brazilian immigrants, indicating probabilities of new migrations or return migration to Brazil.

Keywords: Brazilian migration in Portugal, Portuguese economic crisis, return migration.

Recebido para publicação em 29/09/2014.

Aceito para publicação em 06/11/2014.

Received for publication on September, $29^{\text {th }}, 2014$.

Accepted for publication on November, 06 ${ }^{\text {th }}, 2014$. 